\title{
Waist circumference relates to blood pressure among adults
}

\author{
Meera Dattani ${ }^{1}$, Seema Tanaji Methre,", Tanaji Sambhaji Methre ${ }^{3}$ \\ ${ }^{\mathbf{1}}$ MBBS Student, ${ }^{\mathbf{2}}$ Assistant Professor, Dept. of Physiology, Dr. D. Y. Patil Medical college, Hospital \& Research \\ Centre, Pimpri, Pune, ${ }^{3}$ Consultant, Dept. of Anaesthesiology, Aditya Birla Memorial Hospital, Chinchwad, Pune, \\ India
}

*Corresponding Author:

Email: drseematanaji@yahoo.co.in

\begin{abstract}
Introduction: Approximately 7 million people die every year worldwide due to the deleterious effects of high blood pressure. Increased body weight is a significant risk factor for cardiovascular diseases and their association has been the subject of many studies. The present study was undertaken to examine the presence of obesity on the basis of BMI and to see how different parameters relate with the blood pressure readings in healthy individuals. The parameters measured included body mass index, waist to hip ratio, percentage of total body fat and waist circumference. The correlation of theses parameters with the high blood pressure was studied. We aimed to find out the parameter that would relate more closely to the high blood pressure readings.

Materials and Methods: A cross sectional non-interventional study was conducted after the approval of the ethical committee of the institute. Two hundred subjects of age group 18-20 years were included in the study. Correlation analysis was done using Primer of Biostatistics version 7 software.

Results: A total of 80 males and 120 females took part in the study. The mean age was 18.18 years for males and 18.7 years for females. SBP showed positive and statistically significant correlation with height $(\mathrm{r}=0.5)$, weight $(\mathrm{r}=0.5)$, WC $(\mathrm{r}=0.3)$, WHR $(\mathrm{r}=0.22)$. DBP showed positive and statistically significant correlation with weight $(\mathrm{r}=0.3), \mathrm{BF} \%(\mathrm{r}=0.26)$ and $\mathrm{BMI}(\mathrm{r}=0.24)$.

Conclusion: Obesity and high BP are positively correlated. Waist circumference can be better predictor of obesity related risk than waist hip ratio, body mass index and body fat percentage.
\end{abstract}

Keywords: Blood pressure, Correlation, Obesity, Waist circumference.

Received: $05^{\text {th }}$ October, 2017

Accepted: $09^{\text {th }}$ December, 2017

\section{Introduction}

Approximately 7 million people die every year worldwide due to the deleterious effects of high blood pressure. Overweight and obese individuals are at a higher risk of developing hypertension. Increased BMI and high BP are positively correlated. The presence and severity of obesity can be assessed by measuring waist hip ratio (WHR), BMI and body fat percentage (BF\%). Abnormally increased values of these parameters are directly related to the development of high blood pressure and cardiovascular disease. Abnormal and high value of waist-to-hip ratio is an independent predictor of cardiovascular disease. ${ }^{1}$ The present study was therefore undertaken to examine the presence of overweight and obesity amongst the normal subjects on the basis of BMI and to study the inter-relationship between BMI, WHR, BF\% and waist circumference (WC) with blood pressure.

\section{Materials and Methods}

A cross sectional non-interventional study was conducted after the approval of the ethical committee of the institute. The written informed consent was taken from the subjects. Two hundred subjects of age group 18-20 years were included in the study. Detailed history of all the subjects was taken.

Exclusion Criteria: Subjects with present or past history of any acute or chronic disease state were excluded from the study.

Body weight: This was measured with the subject standing erect and without shoes. Same instrument was used throughout the study.

Height: This was measured with subject standing erect on the floor with the buttocks, shoulders and back of the head touching the wall. The lower border of the orbit was held in the same horizontal plane as the external auditory meatus. The arms were hanging freely by the side of the body. Recording was nearest to 0.5 $\mathrm{cm}$.

Waist circumference (WC): Waist circumference was measuredat midpoint between the iliac crest and last palpable rib in the mid axillary line with measuring tape wrapped snugly at the end of natural breaths. Measuring done was nearest to $0.1 \mathrm{~cm}$. 
Hip Circumference (HC): This was measured at the level of greater trochanters. Measurement was nearest to $0.1 \mathrm{~cm}$.

Waist hip ratio (WHR): Thiswas calculated by the following formula,

WHR = waist circumference $(\mathrm{cm}) /$ hip circumference $(\mathrm{cm}){ }^{2}$

Body composition: Body fat percentage was measured by using the instrument OMRON HBF-306 which is based on the principle of bioelectrical impedance. ${ }^{3}$ The BMI was measured by the same machine with the formula weight $(\mathrm{kg})$ divided by the square of height $\left(\mathrm{m}^{2}\right)$. As per the current WHO guidelines, Obesity and overweight were measured using cut off values as BMI $\geq 30 \mathrm{~kg} / \mathrm{m} 2$ and $\geq 25 \mathrm{~kg} / \mathrm{m} 2$ respectively.

Measuring blood pressure: As perWHO guidelines BP was measured by the digital monitor after 5 mins of rest and in a sitting position. ${ }^{4}$ Three readings were taken with the interval of $3 \mathrm{~min}$ between consecutive measurements. Average values were calculated from the three readings. In order to reduce bias and variations in the BP measurement following things were considered.
1. Same instrument was used throughout the study.

2. An average of three readings was calculated for the analysis.

3. Readings were taken at the same time of the day to minimize the effect of diurnal variation for all the subjects.

4. Abstain from tea, coffee and physical exertion an hour prior to the measurement.

\section{Results}

Data was analyzed using software Primer of Biostatistics version 7.0 after importing it into excel sheet. A total of 80 males and 120 females took part in the study. The mean age was 18.18 years for males and 18.7 years for females with the median age being 19 years for both.

Height, weight, WC, systolic blood pressure (SBP), mean arterial pressure (MAP) and pulse pressure (PP) in males was more and statistically significant compared to females on applying unpaired $\mathrm{t}$ test as seen in Table 1 . Body fat percentage and PR were more and statistically significant in females compared to males as shown in Table 1.

Table 1: Significance of the gender difference between various parameters

\begin{tabular}{|l|c|c|c|}
\hline Parameters & $\begin{array}{c}\text { Males } \\
(\mathbf{n}=\mathbf{8 0}) \\
\text { Mean } \pm \text { SD }\end{array}$ & $\begin{array}{c}\text { Females } \\
(\mathbf{n = 1 2 0}) \\
\text { Mean } \pm \text { SD }\end{array}$ & P value \\
\hline Height & $166.82 \pm 8.31$ & $156.34 \pm 6.76$ & $0.0001^{\ddagger}$ \\
\hline Weight & $66.99 \pm 12.87$ & $57.07 \pm 10.87$ & $0.0001^{\ddagger}$ \\
\hline WC & $77.68 \pm 11.54$ & $73.73 \pm 12.25$ & $0.02^{*}$ \\
\hline HC & $97 \pm 9.39$ & $94.6 \pm 11.36$ & 0.1 \\
\hline WHR & $0.8 \pm 0.07$ & $0.78 \pm 0.09$ & 0.09 \\
\hline BF\% & $25.7 \pm 8.22$ & $29.52 \pm 7.34$ & $0.0001^{\ddagger}$ \\
\hline BMI & $23.9 \pm 4.38$ & $23.66 \pm 4.6$ & 0.7 \\
\hline PR & $85 \pm 10.54$ & $88.67 \pm 10.52$ & $0.01^{*}$ \\
\hline SBP & $112.5 \pm 12.9$ & $105.9 \pm 10.2$ & $0.0001^{\ddagger}$ \\
\hline DBP & $71.5 \pm 7.5$ & $71 \pm 6.57$ & 0.6 \\
\hline MAP & $84.65 \pm 8.2$ & $82.2 \pm 6.9$ & $0.02^{*}$ \\
\hline PP & $41 \pm 10.92$ & $34.91 \pm 8.23$ & $0.0001^{\ddagger}$ \\
\hline
\end{tabular}

Statistically significant at $\mathrm{p}^{*<0.05,} \mathrm{p}^{\dagger}<0.01, \mathrm{p}^{*}<0.001$.WC: Waist circumference, HC: Hip circumference, WHR: Waist hip ratio, BF\%: Body fat percentage, BMI: Body mass index, PR: Pulse rate, SBP: Systolic blood pressure, DBP: Diastolic blood pressure, MAP: Mean arterial pressure, PP: Pulse pressure.

In males, SBP showed positive and statistically significant correlation with height, weight, WC, and WHR (Table 2). DBP showed positive and statistically significant correlation with weight, BF\% and BMI (Table 2). In females, SBP showed positive and statistically significant correlation with weight (Table 3). Percentage of overweight subjects was more in males but percentage of obesity was more in females (Table 4). Percentage of pre-hypertension and hypertension was more and statistically significant in males (Table 5). 
Table 2: Correlation between systolic blood pressure, diastolic blood pressure, mean arterial pressure and pulse pressure with various parameters (males)

\begin{tabular}{|l|l|l|l|l|l|l|l|}
\hline $\begin{array}{c}\text { Blood } \\
\text { pressure }\end{array}$ & Height & Weight & WC & HC & WHR & BF\% & BMI \\
\hline SBP & $0.5^{\ddagger}$ & $0.5^{\ddagger}$ & $0.3^{*}$ & 0.18 & $0.22^{*}$ & -0.08 & 0.20 \\
\hline DBP & 0.15 & $0.30^{\dagger}$ & 0.17 & 0.17 & 0.10 & $0.26^{*}$ & $0.24^{*}$ \\
\hline
\end{tabular}

Correlation significant at: $\mathrm{p}^{*<0.05,} \mathrm{p}^{\dagger}<0.01, \mathrm{p}^{*}<0.001$. WC: Waist circumference, HC: Hip circumference, WHR: Waist-to- hip ratio, BF\%: Body fat percentage, BMI: Body mass index, SBP: Systolic blood pressure, DBP: Diastolic blood pressure, MAP: Mean arterial pressure, PP: Pulse pressure

Table 3: Correlation between systolic blood pressure, diastolic blood pressure, mean arterial pressure and pulse pressure with various parameters (Females)

\begin{tabular}{|l|l|l|l|l|l|l|l|}
\hline $\begin{array}{c}\text { Blood } \\
\text { pressure }\end{array}$ & Height & Weight & WC & HC & WHR & BF\% & BMI \\
\hline SBP & 0.08 & $0.25^{\dagger}$ & 0.13 & 0.04 & 0.14 & 0.07 & 0.16 \\
\hline DBP & -0.02 & 0.1 & 0.16 & 0.16 & 0.05 & 0.09 & 0.14 \\
\hline
\end{tabular}

Correlation significant at: $\mathrm{p}^{*}<0.05, \mathrm{p}^{\dagger}<0.01$. WC: Waist circumference, HC: Hip circumference, WHR: Waist-to- hip ratio, BF\%: Body fat percentage, BMI: Body mass index, SBP: Systolic blood pressure, DBP: Diastolic blood pressure, MAP: Mean arterial pressure, PP: Pulse pressure

Table 4: Overweight \& obesity

\begin{tabular}{|l|c|c|}
\hline \multicolumn{1}{|c|}{ Body mass index } & Males\% (Number) & Females\% (Number) \\
\hline Normal weight & $48.75(39)$ & $50.83(61)$ \\
\hline Under weight & $8.75(7)$ & $12.5(15)$ \\
\hline Over weight & $36.25(29)$ & $26.66(32)$ \\
\hline Obese & $6.25(5)$ & $10(12)$ \\
\hline
\end{tabular}

BMI and Gender, chi-square $=2.89$ (non-significant)

Table 5: Pre-hypertension andHypertension

\begin{tabular}{|l|c|c|c|c|}
\hline \multirow{2}{*}{ Blood pressure } & \multicolumn{2}{|c|}{ Males \% (Number) } & \multicolumn{2}{c|}{ Females \% (Number) } \\
\cline { 2 - 5 } & SBP & DBP & SBP & DBP \\
\hline Normal & $73.75(59)$ & $81.25(65)$ & $89.16(107)$ & $92.5(9)$ \\
\hline Pre-hypertension & $23.75(19)$ & $18.75(15)$ & $10.83(13)$ & $7.5(9)$ \\
\hline Hypertension & $2.5(2)$ & 0 & 0 & 0 \\
\hline
\end{tabular}

DBP and Gender chi-square $=4.737^{*}(\mathrm{p}<0.05)$, SBP and Gender chi-square $=9.38^{\dagger}(\mathrm{p}<0.01)$. SBP: Systolic blood pressure, DBP: Diastolic blood pressure

\section{Discussion}

In this study, we found that mean values of height, weight and waist circumference in males were more and statistically significant compared to females. Similar results were obtained by Dua et al and Mushengezi B and Cillo P. ${ }^{5,6}$ However value of body fat percentage was more and statistically significant in females compared to males. Mushengezi $\mathrm{B}$ and Cillo $\mathrm{P}^{[6]}$ reported similar findings in a study carried out in secondary school adolescents as subjects. Pulse rate was more and statistically significant in females compared to males as was also observed by Moselakgomo VK et al. ${ }^{7}$ Systolic blood pressure, mean arterial pressure and pulse pressure were found to be more and statistically significant in males compared to females.
Similar findings are recorded by Moselakgomo VK et al and Reckelhoff JF. ${ }^{7,8}$

Blood pressure in adults is related to various indices of body build. Weight is positively associated with blood pressure but stature shows little relationship with it. There is evidence that increased body weight in adults is predominantly due to an increase in the amount of fat. ${ }^{9}$ The association of blood pressure with body weight could be due to the increased total body mass or to some special underlying relationship between blood pressure and body fat resulting from differences in microcirculation in fat tissue.

Several studies have been done in different parts of India on factors affecting cardiovascular function. Obesity or excess relative weight is found to be associated with increased risk of disease morbidity and mortality. ${ }^{5}$ 
Men are generally at greater risk for cardiovascular and renal disease than are agematched premenopausal women. Recent studies using the technique of 24-hour ambulatory blood pressure monitoring have shown that blood pressure was higher in men than in women at similar ages. The key factor in controlling the pressure-natriuresis relationship is the reninangiotensin system (RAS). The possibility that androgens increase blood pressure via the RAS has been explored, and the possibility that the RAS also promotes oxidative stress leading to production of vasoconstrictor substances and reduction in nitric oxide availability has been proposed. ${ }^{8}$ An inhibitory effect of estradiol on the activation of the RAAS (RenninAngiotensin-Aldosterone System) in premenopausal women has been explained by Seely et al. ${ }^{10}$ It may play an important role in lowering BP in premenopausal women.

On regression analysis, systolic blood pressure showed positive and statistically significant correlation with height and weight in males. SBP also showed correlation which is positive and statistically significant with waist circumference and waist hip ratio in males but not seen in females. Similar finding was seen by Dua $S$ et al., Reckelhoff JF and Guagnano MT etal. ${ }^{5,8,2}$ Diastolic blood pressure showed poor correlation with weight, body fat percentage and body mass index in males but not in females.

Influence of the sex-dependent body fat distribution on the relationship between body weight and blood pressure in obese hypertensive subjects has been studied. ${ }^{11,12}$ The association of blood pressure with body weight and other indices of fatness such as skin fold thickness has been shown by many epidemiological studies. ${ }^{2,13,15,16}$ Though multiple studies have shown that obesity and hypertension are related, the exact nature of such a relationship is quite complex in nature. Because of this reason the correlation coefficients in these studies have been constantly small. ${ }^{12,11}$

Kanai et $\mathrm{al}^{17}$ studied the relationship between intra-abdominal fat and the high blood pressure in obese females. They reported that such a relationship was independent of the age of the female and her body mass index. This suggests that there's a role for the intra abdominal visceral fat accumulation in the pathogenesis of hypertension in obese individuals. Lurbe and colleagues ${ }^{18}$ carried out ambulatory blood pressure measurements in adolescents and compared them with the body fat distribution. They found that a high value of waist to hip circumference ratio was independently associated with the high blood pressure readings. This association was maintained irrespective of whether the ambulatory blood pressure recordings were taken during the whole 24 hours period, during the night or during the day time. This further establishes the close association between the high waist to hip circumference ratios and hypertension.

Recent research in the complex relationship of obesity and cardiovascular disease has been more focused on the patterns of distribution of body fat rather than the percentage of total body fat. It is believed that the nature of abdominal adipose tissue is different from adipose tissue elsewhere in the body at the cellular level. For these reasons waist circumference assumes greater significance and is a better predictor of health risks posed by the obesity. Thus waist circumference is a useful index of obesity and predicts risk better than BMI. ${ }^{19}$ Similar inferences could be drawn from a study by Lean et al. ${ }^{20}$ Waist circumference shows total abdominal fat accumulation which is not influenced by height. ${ }^{21}$

Waist circumference predicted mortality better than other anthropometric parameters. ${ }^{22}$ Increased WC was also associated with diabetes, stroke and coronary heart disease. ${ }^{23}$ Cardiovascular disease was also associated to abdominal adiposity which can be estimated by skin fold measurement and WC. ${ }^{[24]} \mathrm{WC}$ is the best anthropometric parameter correlating with the amount of visceral adipose tissue. ${ }^{25}$ That the change in waist circumference leads to change in visceral adipose tissue disposition has been shown by longitudinal studies. ${ }^{26} \mathrm{WC}$ gives information about general as well as abdominal obesity including both abdominal subcutaneous fat and visceral adipose tissue. It may show sensitivity to weight changes due to exercise, diet, smoking and alcohol consumption. ${ }^{27}$

Waist hip ratio captures body fat distribution. However, change in waist circumference was a better correlate of the change in visceral adipose tissue than the change in the waist-hip ratio. ${ }^{26}$ Waist hip ratio shows relative accumulation of abdominal fat, while WC shows absolute abdominal fat as well as total body weight. Two circumference measures are required for waist hip ratio calculation. Both measurements are subject to measurement errors. The results of this study show that the waist circumference is a good predictor of risk in this population.

The relationship between obesity and hypertensive risk is confirmed by this study. This study also showed that waist circumference is better than waist hip ratio and body fat 
percentage in predicting obesity related increased risk of cardiovascular disease.

Our study also showed that the percentage of overweight was higher in males $(36.25 \%)$ compared to females $(26.66 \%)$ but the percentage of obesity was higher in females (10\%) compared to males $(6.25 \%)$.

This study also showed that the percentage of pre-hypertension and hypertension was higher in males compared to females for both systolic BP $(p<0.01)$ as well as diastolic BP $(p<0.05)$ which was statistically significant on applying Chi square test as seen by Reckelhoff JF. ${ }^{8}$

\section{Conclusion}

The relationship between obesity and hypertensive risk was confirmed by this study. Waist circumference can be better predictor of obesity. Waist circumference was better correlated with blood pressure. Due to its simplicity and greater ability to predict the risk, we suggest inclusion of waist circumference measurement as a routine part of general physical examination by clinicians along with the height, weight and BMI.

\section{Acknowledgement}

The authors are thankful to all the subjects. We acknowledged the support of ICMR as this was ICMR STS project. We are grateful to ICMR for giving us opportunity for doing this work.

\section{References}

1. Badaruddoza, Navneet Kaur and Basanti Barna, "Inter-relationship of waist-to-hip ratio (WHR), body mass index (BMI) and subcutaneous fat with blood pressure among university-going Punjabi Sikh and Hindu females" International Journal of Medicine and Medical Sciences (2010) 2(1),005-11.

2. Guagnano MT, Ballone E, Colagrande V, Vecchia RD, Manigrasso MR, Merlitti D, Riccioni G and Sensi S, "Large waist circumference and risk of hypertension" International Journal of Obesity (2001)25,1360-4.

3. Verma Vivek, Singh SK. "Influence of lean body mass index versus that of fat mass index on blood pressure of gujarati school going adolescents" Indian J Physiol Pharmacol (2014)58(1),39-44.

4. Chobanian AV, Bakris GL, Black HR, Cushman WC, Green LA, Izzo Jr JL et al, "The seventh report of the Joint National Committee on Prevention, Detection, Evaluation, and Treatment of High Blood Pressure: The JNC 7 Report" JAMA (2003) 289, 2560-72.

5. Dua S, Bhutkar M, Sharma P, Dhall M, Kapoor $\mathrm{S}$, "Body Mass Index Relates to Blood
Pressure among Adults" North American Journal of Medical Sciences (2014)6(2),89-95.

6. Mushengezi B, Chillo P, “Association between body fat composition and blood pressure level among secondary school adolescents in Dar es Salaam, Tanzania" Pan African Medical Journal (2014)19,1-12.

7. Moselakgomo VK, Toriola A, Shaw BS, Goon DT, Akinyemi O, "Body mass index, overweight, and blood pressure among adolescent schoolchildren in Limpopo province, South Africa.Rev Paul" Pediatr (2012)30,562-9.

8. Reckelhoff JF, "Gender differences in the regulation of blood pressure" Hypertension (2001)37,1199-208.

9. Forbes GB, "Body composition in adolescence" In Human Growth: PostnatalGrowth, edited by Falkner F, Tanner JM. New York: Plenum Press, (1978) 2,239-72

10. Seely EW, Walsh BW, Gerhard MD \& Williams GH, "Estradiol with or without progesterone and ambulatory blood pressure in postmenopausal women" Hypertension (1999)33,1190-4.

11. Raison JM, Achimastos AM, Safar ME, "Sexdependence of body fat distribution in patients with obesity and hypertension" Clin Exp Hypertens (1992)14,505-25.

12. Guagnano MT, Ballone E, Merlitti D, Murri R, Pace-Palitti V, Pilotti R, Sensi S, "Association between anthropometric and ultrasound measurements of fatness with ambulatory blood pressure monitoring in obese women" Int J Obes Relat Metab Disord (1997)21,6326.

13. Ledoux M, Lambert J, Reeder BA, Despres JP, "Correlation between cardiovascular disease risk factors and simple anthropometric measures" Canadian Heart Health Surveys Research Group.CMAJ (1997)157(Suppl 1):S46-53.

14. Ko GT, Chan JC,Woo J, Lau E, Yeung VT, Chow CC,Wai HP, Li JK,So WY, Cockram CS, "Simple anthropometric indexes and cardiovascular risk factors in Chinese" Int J Obes Relat Metab Disord (1997)21,995-1001.

15. Cox BD, Whichelow MJ, Prevost AT, "The development of cardiovascular disease in relation to anthropometric indices and hypertension in British adults" Int J Obes Relat Metab Disord (1998)22,966-73.

16. Okosum IS, Forrester TE, Rotimi CN, Osotimehin BO, Muna WF, Cooper RS, "Abdominal adiposity in six population of West African descent: prevalence and population attributable fraction of hypertension" Obes Res (1999)7,453-62.

17. Kanai H, Matsuzawa Y, Kotani K, Keno Y, Kobatake T, Nagai Y, Fujioka S, Tokunaga K, Tarui S, "Close correlation of intra-abdominal fat accumulation to hypertension in obese women" Hypertens (1990)16,484-90.

18. Lurbe E, Alvarez V, Liao Y, Tacons J, Cooper R, Cremades B, Torro I, Redon J, "The impact of obesity and body fat distribution on ambulatory blood pressure in children and 
adolescents” Am J Hypertens (1998)11,418-

24.

19. Han TS, van Leer EM, Seidell JC, Lean MEJ,

"Waist circumference action levels in the

identification of cardiovascular risk factors:

prevalence study in a random sample" $\mathrm{Br}$ Med J (1995)311,1401-5.

20. Lean MEJ, Hans TS, Morrison CE, "Waist circumference as a measure for indicating need for weight management" Br Med J (1995)311,158-61.

21. Han TS, Seidell JC, Curral JEP, Morrison C, Deuremberg P, Lean MEJ, "The influence of height and age on waist circumference as an index of adiposity in adults" Int J Obes Relat Metab Disord (1997)21,83-9.

22. Higgins M, Kannel W, Garrison R, Pinsky J \& Stokes III J, "Hazards of obesity-the Framingham experience" Acta Med. Scand (1988)723, 23-36.

23. Dey DK, Rothenberg E, Sundh V, Bosaeus I \& Steen B, "Waist circumference, body mass index, and risk for stroke in older people: a 15 year longitudinal population study of 70- yearolds" J. Am. Geriatr Soc (2002)50,1510-8.

24. Kannel WB, Cupples LA, Ramaswami R, Stokes III J, Kreger BE \& Higgins M, "Regional obesity and risk of cardiovascular disease; the Framingham Study" J. Clin. Epidemiol (1991) 44,183-90.

25. Pouliot MC, Despres JP, Lemieux S, Moorjani S, Bouchard C, Tremblay A, Nadeau A \& Lupien PJ, "Waist circumference and abdominal sagittal diameter: best simple anthropometric indexes of abdominal visceral adipose tissue accumulation and related cardiovascular risk in men and women" Am. J. Cardiol (1994)73,460-8.

26. Lemieux S, Prud'homme D, Tremblay A, Bouchard C \& Despres JP, "Anthropometric correlates to changes in visceral adipose tissue over 7 years in women" Int. J. Obes.

Relat.Metab. Disord. (1996)20,618-24.

27. Vadstrup ES, Petersen L, Sorensen TI \&

Gronbaek M, "Waist circumference in relation to history of amount and type of alcohol: results from the Copenhagen City Heart Study" Int.J.Obes. Relat. Metab. Disord

(2003)27,238-46. 